\title{
ASSESSMENT OF COMPLIANCE TO TREATMENT IN TYPE II DIABETES
}

\author{
Bolimera Venkata Sudheer ${ }^{1}$, M. Varalakshmi²
}

${ }^{1}$ Associate Professor, Department of General Medicine, NIMS (Nimra Institute of Medical Sciences), Jupudi, Ibrahimpatnam, Vijayawada, Krishna District, Andhra Pradesh.

2Senior Resident, Kanumuri Hospital, Kothapeta, Guntur, Andhra Pradesh.

\section{ABSTRACT}

\section{BACKGROUND}

The burden of Diabetes in India is increasing day by day. But regarding treatment compliance in Diabetics not satisfactory in India. It is a serious risk factor for morbidity and mortality. To assess the compliance to treatment among Diabetic patients and to study reasons for the non-compliance this study was conducted. This study finds very high levels of non-adherence to the treatment due to lack of awareness and healthcare facilities. The most common reasons of non-compliance is the lack of sufficient motivation for the treatment adherence as many mentioned is $61.4 \%$ in diabetics.

In the study of Ludhiana, one of the important reasons of non-compliance was found as cost of checkup in $27 \%$ subjects, while $15.7 \%$ of subjects mentioned long distance between household and health facility as a reason. ${ }^{1}$

\section{MATERIALS AND METHODS}

Observational study was conducted in the Diabetic population attending to this Hospital. All the cases of Diabetes diagnosed for more than 1 year were included in the study. A structured and pretested questionnaire was administered including the treatment details and factors assessing the compliance, knowledge and attitude towards the diabetic disease.

Exclusion Criteria- Type 1 Diabetics, Type 2 Diabetics diagnosed and taking treatment less than 1 year.

\section{RESULTS}

A total of 105 individuals were included in the study. The age of onset/detection of Diabetes is more common at the age of $36-45$ yrs. in females, and at the age of 46 - 55 yrs. in males. In this study, 48.5\% (51) were middle and 40\% (42) belonged to lower socioeconomic condition. The Literacy among these diabetics were 59\% (62) uneducated/below graduation and 25\% (26) having graduation and $16 \%$ (17) above graduation; $37 \%$ of the individuals are unaware of sticking to the treatment and $27 \%$ are unaware about the course and Diabetic complications (micro or macro) and 36\% are unaware that medication will delay the Diabetic complications; 79 (75\%) were found taking drug treatment regularly since 1 year, 22 (21\%) never discontinued the drug treatment since the onset/detection of diabetes. The non-compliance was due to the lack of faith in the medication 12 (11\%), forgetfulness of daily medication 61 (58\%) and financial constraints for the drug treatment 32 (31\%). The diet non-adherence was $58 \%(62)$. The diet non-adherence was due to dislike for foods included in meal plans $47 \%$, social influences were $47 \%$ and $6 \%$ are not able to follow the meal plan due to financial constraints, $91.5 \%$ (96) were non-adherent to exercise. The lack of motivation was noticed in $27 \%$ (50), lack of planning in $51 \%$ (50) and physical problems $22 \%$ (42).

\section{CONCLUSION}

Type 2 Diabetes is a progressive disease and needs Pharmacological treatment along with Diet, exercise, lifestyle changes which are essential to maintain glycaemic control and to reduce the complications. The non-adherence to Pharmacological treatment, diet, exercise, lifestyle changes are the main reasons for the failure in the Diabetic management. For efficient control of Diabetic management, the causes of non-adherence have to be perceived and corrected.

Among the numerous reasons for poor adherence include lack of understanding of long-term benefits of treatment due to low education status of the community, lack of faith in the treatment and motivation, unawareness and self-neglect, financial constraints and lack of communication between doctor and the patient, all of these lead to non-compliance. ${ }^{2}$

According to the Health Belief Model (HBM), individuals will be more likely to adhere to medical regimen if they believe that the benefits (perceived benefits) of the behaviours considered are immense and such behaviour is both possible and useful. ${ }^{3}$

\section{KEYWORDS}

Type II Diabetes, Glycaemic Control, Adherence, Non-Compliant, Non-Communicable Diseases (NCDs).

HOW TO CITE THIS ARTICLE: Sudheer BV, Varalakshmi M. Assessment of compliance to treatment in type II diabetes. J. Evolution Med. Dent. Sci. 2017;6(41):3235-3239, D0I: 10.14260/Jemds/2017/701

Financial or Other, Competing Interest: None.

Submission 04-04-2017, Peer Review 12-05-2017,

Acceptance 17-05-2017, Published 22-05-2017.

Corresponding Author:

Dr. Bolimera Venkata Sudheer

A2 Kanishq Apartments, JKC Nagar

$1^{\text {st }}$ Lane, Guntur - 522006, Andhra Pradesh.

E-mail: bvsudheer9@gmail.com

DOI: $10.14260 /$ jemds $/ 2017 / 701$

\section{BACKGROUND}

Non-Communicable Diseases (NCDs) are chronic diseases of long duration and slow progression and are not transferable from one person to other. The four main types of NCDs are cardiovascular diseases, cancers, chronic respiratory diseases and diabetes mellitus. The NCDs are leading cause of mortality, worldwide with $80 \%$ of NCDS deaths in the low and middle income countries. The increase in type 2 diabetes is associated with obesity, hypertension and an increasingly elderly population. However, despite strong clinical 
recommendations for individuals with a history of diabetes to adopt a healthier lifestyle, adherence to improved diet and exercise is poor. ${ }^{[4]}$ The World Health Organisation (WHO) has shown that adherence to long-term therapy for chronic illnesses in developed countries averages only around $50 \% .{ }^{[4]}$ Such reduced adherence not only results in poor health outcomes, but it also has a significant impact on healthcare.

\section{MATERIALS AND METHODS}

Observational study was conducted in the Diabetic population attending to this Hospital. All the cases of Diabetes diagnosed for more than 1 year were included in the study. A structured and pretested questionnaire was administered including the medical documentation, treatment details and factors assessing the compliance, knowledge and attitude towards the diabetic disease.

This study was attempted to address the issues of Diabetic that can be controlled with patient awareness, timely diagnosis and intervention. All the known cases of diabetes as identified by the Physician and on anti-diabetic medications (self-reported) for more than one year were included in the study.

Effort was made to obtain the nearest possible birth date of each patient. Existing blood sugar levels over the period since diagnosis of diabetes was checked to verify the level of compliance according to WHO criteria of Fasting blood sugar less than $126 \mathrm{mg} / \mathrm{dL}$ and/or Post-Prandial blood sugar of less than $200 \mathrm{mg} / \mathrm{dL}$ as under control. ${ }^{5}$

The term adherence for use is chronic disorders as the extent to which a person "taking medication as prescribed and/or agreed between the patients and the healthcare provider."

"Non-compliant"- categorical endpoints (e.g. 90\%) below which patients were considered "non-compliant" with the regimen. On compliance can be divided into categories. Primary non-compliance occurs when the patients fail to have the medication dispensed. Secondary non-compliance occurs when it is not taken as instructed. Intentional noncompliance may occur when the doctor's diagnosis or treatment is rejected by the patient. Unintentional noncompliance can be related to social, demographic, psychological and clinical varieties. Ex. retinopathy, neuropathy who is unable to see or feel and developing foot ulcer and therefore does not comply to seek medical attention.

Methods of measuring adherence can be either direct (biological marker) which is more sensitive, but can be invasive and is not usually practical or indirect (selfreporting, questionnaires, pill counts). Adherence is usually regarded as the proportion of patients taking at least $80 \%$ of their prescribed medication, but this cut-off can be up to $90 \%$ in some studies. ${ }^{6}$

\section{RESULTS}

\begin{tabular}{|c|c|c|}
\hline Age at Onset & Male & Female \\
\hline $25-35$ & 6 & 11 \\
\hline $36-45$ & 17 & 12 \\
\hline $46-55$ & 15 & 15 \\
\hline $56-65$ & 15 & 12 \\
\hline \multicolumn{2}{|c|}{ Table 1. Ages at Onset/Detection of Morbidity } \\
\hline
\end{tabular}

The age of onset/detection of Diabetes is more common at the age of 36 - $45 \mathrm{yrs}$. in females, and at the age of $46-55$ yrs. in the males.

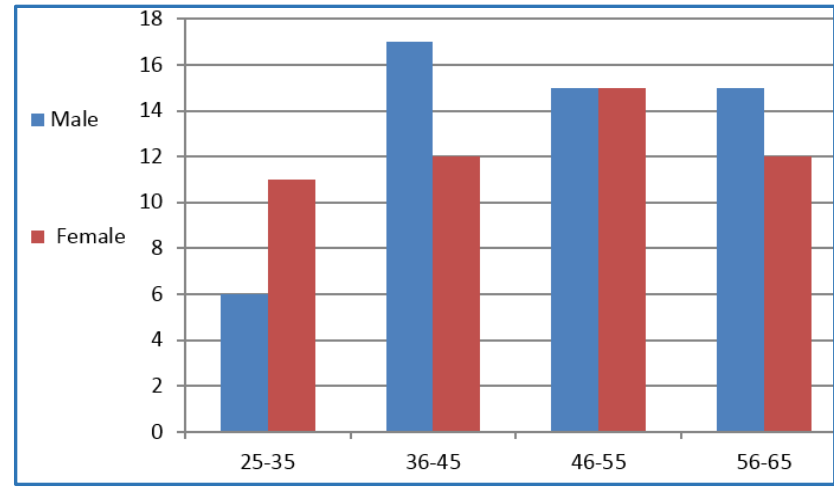

Figure 1

Socioeconomic Class Distribution

Table 2 and Figure 2 showing the socioeconomic status of the individuals in the study.

\begin{tabular}{|c|c|c|}
\hline \multicolumn{3}{|c|}{ Socioeconomic Distribution } \\
\hline Lower & Middle & High \\
\hline 42 & 51 & 12 \\
\hline \multicolumn{3}{|c|}{ Table 2 } \\
\hline
\end{tabular}

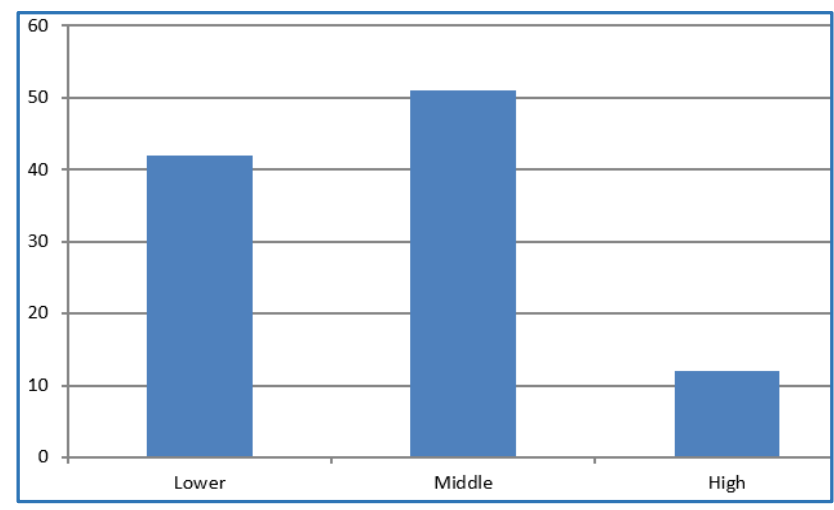

Figure 2

Literacy Distribution

Table 3 and Figure 3 showing literacy statuses of the individuals in the study.

\begin{tabular}{|c|c|c|}
\hline $\begin{array}{c}\text { Uneducated and } \\
\text { below Graduation }\end{array}$ & Graduation & $\begin{array}{c}\text { Above } \\
\text { Graduation }\end{array}$ \\
\hline 62 & 26 & 17 \\
\hline \multicolumn{3}{|c|}{ Table 3 } \\
\hline
\end{tabular}

\section{Literacy Distribution}

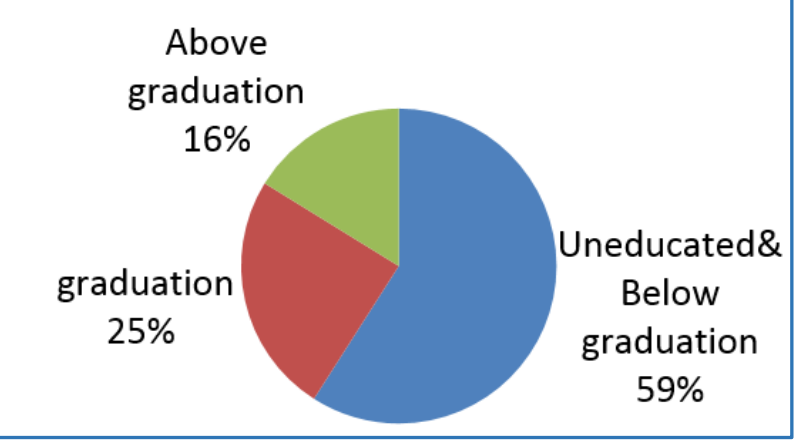

Figure 3 
Treatment Awareness

Table 4 and Figure 4 showing the Treatment Awareness

\begin{tabular}{|c|c|c|c|c|}
\hline Aware & $\begin{array}{c}\text { Un- } \\
\text { aware }\end{array}$ & $\begin{array}{c}\text { Awareness } \\
\text { to stick to } \\
\text { Treatment }\end{array}$ & $\begin{array}{c}\text { Awareness } \\
\text { of Course, and } \\
\text { Complications }\end{array}$ & $\begin{array}{c}\text { Awareness of } \\
\text { Medication delay } \\
\text { the } \\
\text { Complications }\end{array}$ \\
\hline 74 & 31 & 31 & 22 & 30 \\
\hline \multicolumn{4}{|c|}{ Table 4 } \\
\hline
\end{tabular}

\section{figure 4 Awarness of Disease}
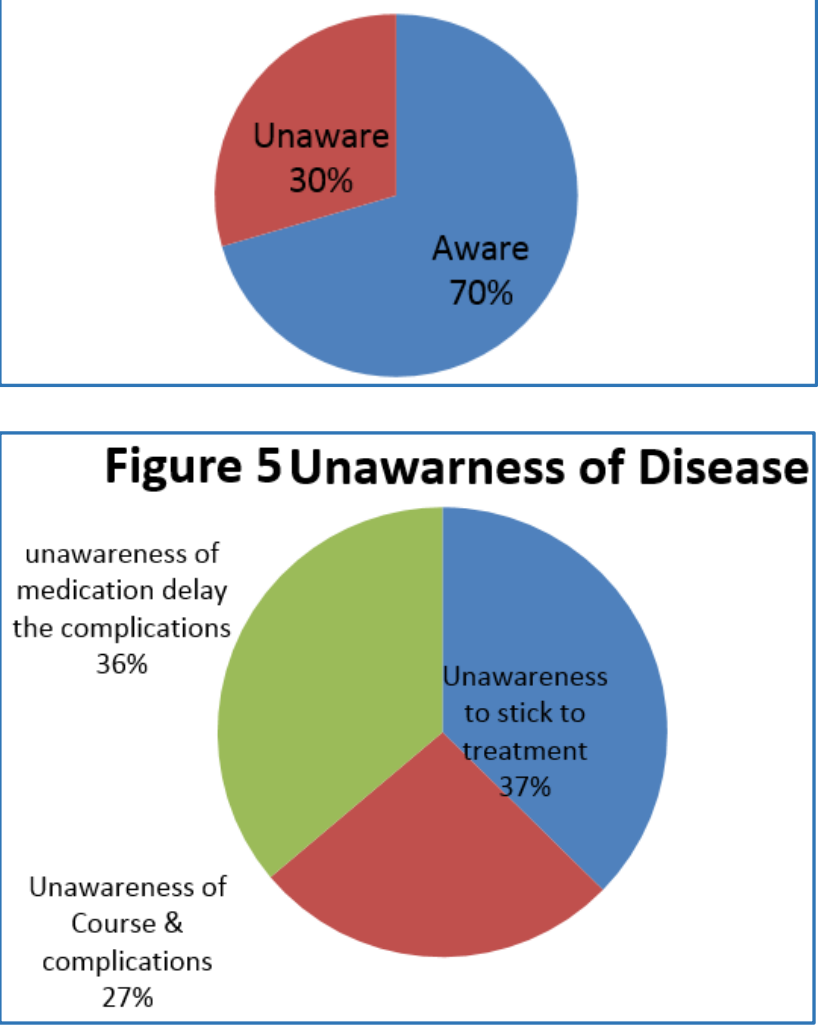

$37 \%$ of the individuals are unaware of sticking to the treatment and $27 \%$ are unaware about the course and its complications (micro or macro) and $36 \%$ are unaware that medication will delay the complications.

\section{Drug Adherence}

Table 5 and Figure 6 showing the adherence to the drug treatment since the onset/detection of Diabetes and since last one-year period.

\begin{tabular}{|c|c|}
\hline $\begin{array}{c}\text { On Regular Drug } \\
\text { Treatment since 1 yr. }\end{array}$ & $\begin{array}{c}\text { On Regular Drug } \\
\text { Treatment since Detection }\end{array}$ \\
\hline 79 & 22 \\
\hline \multicolumn{2}{|c|}{ Table 5 } \\
\hline
\end{tabular}

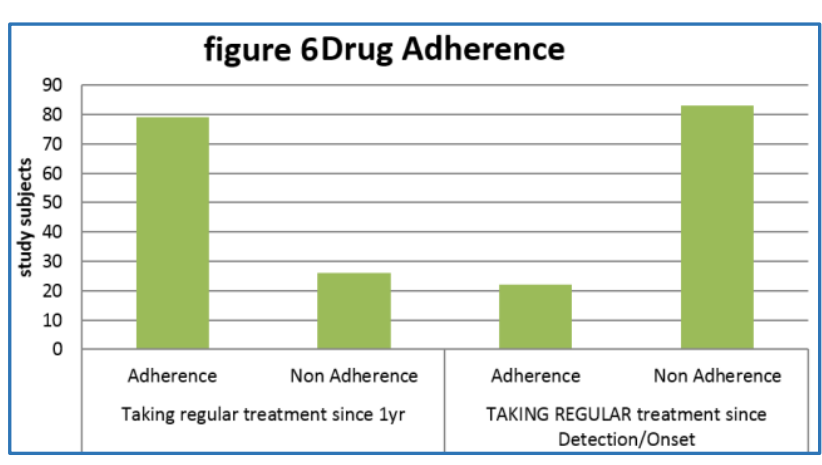

Figure 7 Regular treatment since 1 year

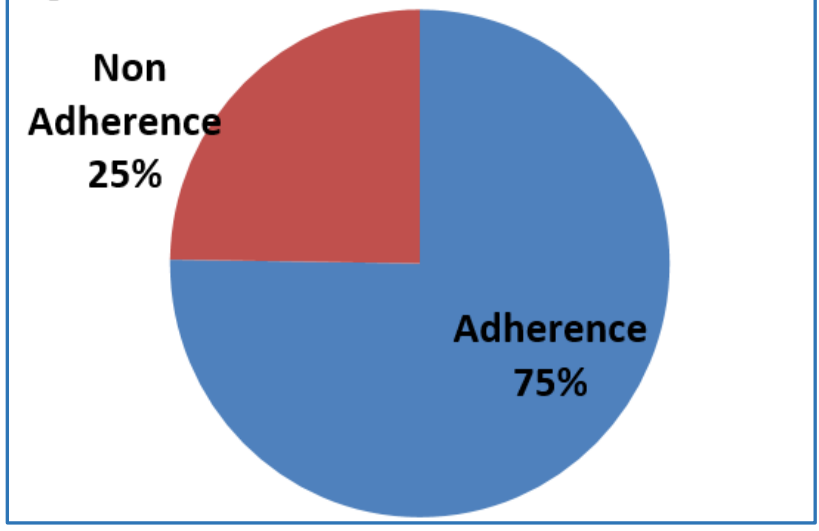

Figure 8 Regular Drug treatment since Onset

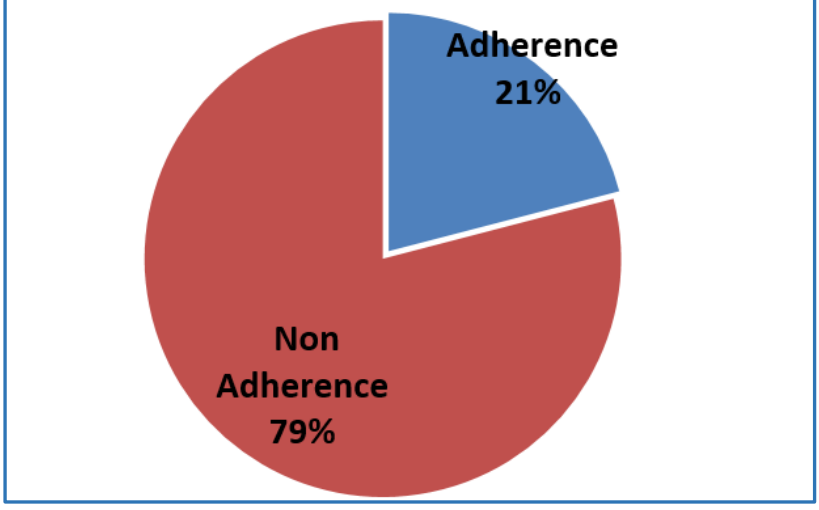

$79(75 \%)$ were found taking drug treatment regularly since 1 year at the time of interview; 22 (21\%) of the participants never discontinued the drug treatment since the onset/detection of diabetes.

Attitude towards regular Drug treatment

\begin{tabular}{|c|c|c|}
\hline $\begin{array}{c}\text { Lack of Faith } \\
\text { in the Treatment }\end{array}$ & $\begin{array}{c}\text { Forgetfulness of } \\
\text { Daily Medication }\end{array}$ & $\begin{array}{c}\text { Financial } \\
\text { Constraints for the } \\
\text { Drug Treatment }\end{array}$ \\
\hline 12 & 61 & 32 \\
\hline \multicolumn{2}{|c|}{ Table 6 } \\
\hline
\end{tabular}

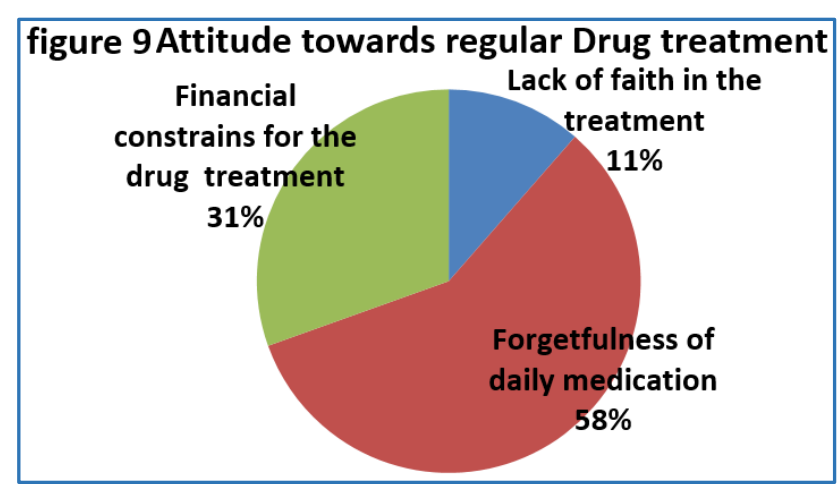


Diet Adherence

Table 7, Figure 10 and 11 showing the Diet adherence

\begin{tabular}{|c|c|c|c|}
$\begin{array}{c}\text { Non- } \\
\text { adherence }\end{array}$ & $\begin{array}{c}\text { Dislike for } \\
\text { Foods } \\
\text { included } \\
\text { in the Meal } \\
\text { Plan }\end{array}$ & $\begin{array}{c}\text { Social } \\
\text { Influences } \\
\text { (Parties/ } / \\
\text { Functions) }\end{array}$ & $\begin{array}{c}\text { Not able to } \\
\text { follow the Meal } \\
\text { Plan due to } \\
\text { Financial } \\
\text { Constraints }\end{array}$ \\
\hline 62 & 47 & 47 & 5 \\
\hline \multicolumn{3}{|c|}{ Table 7 } \\
\hline
\end{tabular}
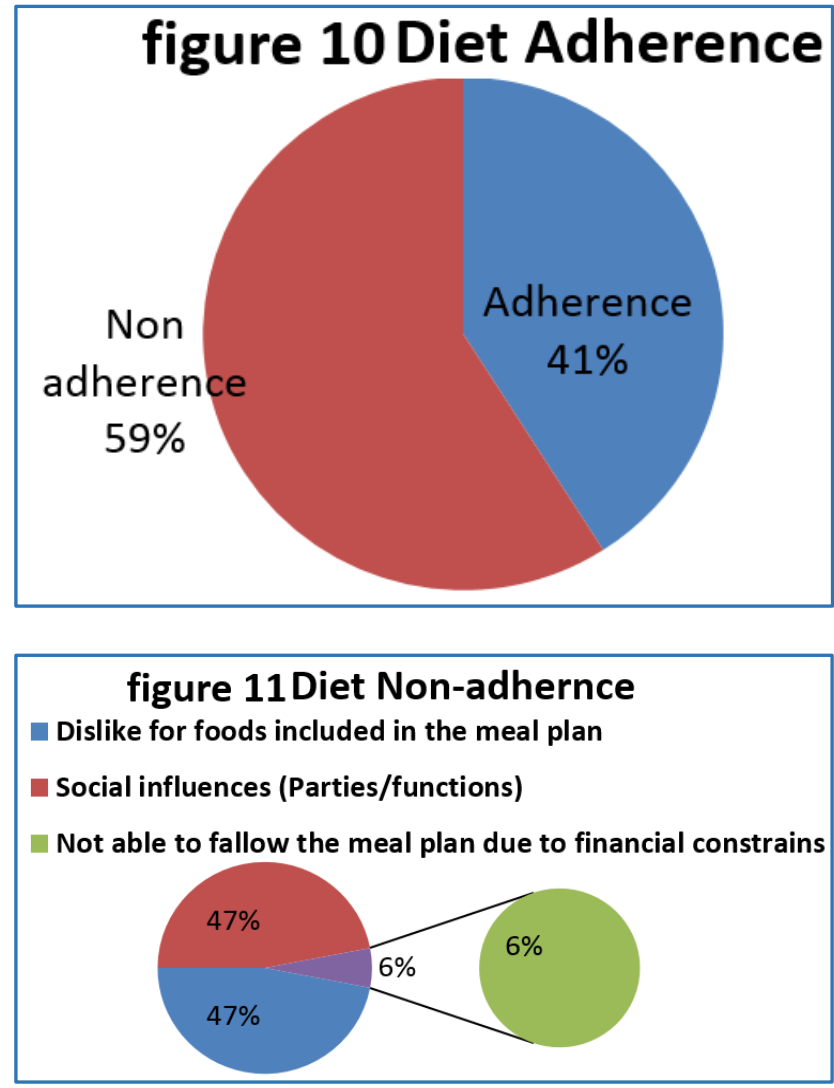

\begin{tabular}{|c|c|c|c|}
\hline $\begin{array}{c}\text { Non- } \\
\text { adherence }\end{array}$ & $\begin{array}{c}\text { Lack of } \\
\text { Motivation }\end{array}$ & $\begin{array}{c}\text { Physical } \\
\text { Problems }\end{array}$ & $\begin{array}{c}\text { Lack of } \\
\text { Planning }\end{array}$ \\
\hline 96 & 50 & 42 & 50 \\
\hline \multicolumn{3}{|c|}{ Table 8. Exercise Adherence } \\
\hline
\end{tabular}

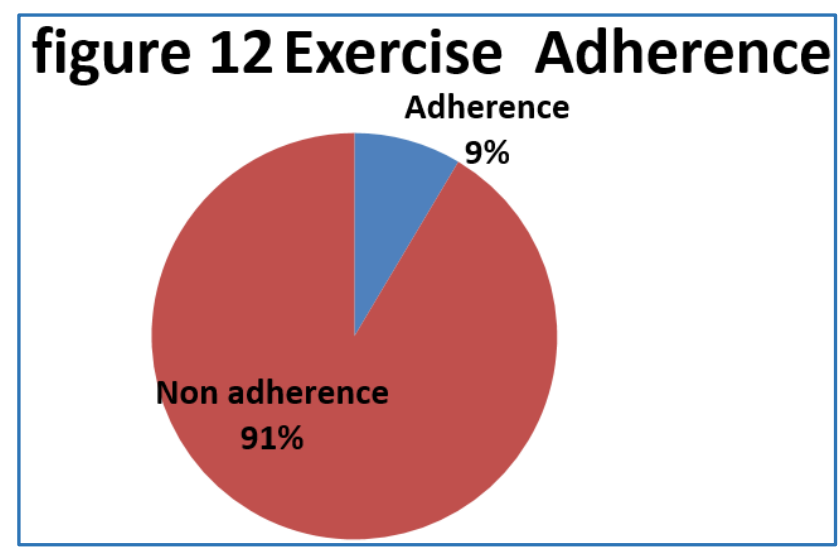

figure 13Exercise Non-adherence

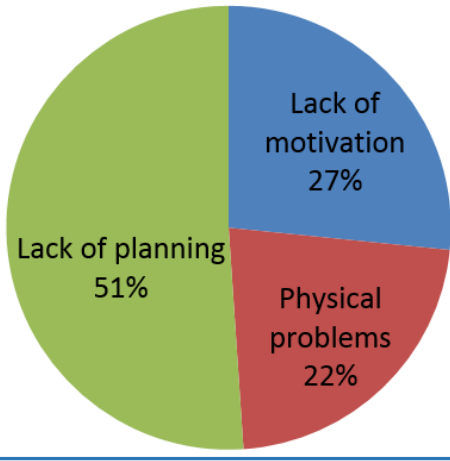

91.5\% (96) were non-adherent to Exercise. The factors that influence adherence to exercise include lack of motivation $27 \%,{ }^{[7]}$ physical problems $22 \%$ and lack of planning $51 \%$ are the prominent barriers to adherence.

\section{DISCUSSION}

In India, ${ }^{8}$ Non-communicable Diseases are estimated to account for $60 \%$ of total deaths. Proportional mortality comparison shows that deaths due to diabetes alone are up to $2 \%$, while deaths due to cardiovascular diseases account for $26 \%$. A total of 105 individuals were included in the study. The age of onset/detection of Diabetes is more common at the age of $36-45 \mathrm{yrs}$. in females and at the age of $46-55 \mathrm{yrs}$. in the males. Though, there is no socioeconomic discrimination for the onset of the Diabetes, but in this study more cases were reported in the middle (48\%) and lower (40\%) income groups. In this study, 59\% (62) of the individuals are uneducated/below graduation and 25\% (26) having graduation and 16\% (17) having above graduation. Literacy and awareness are the important factors in the prevention of the disease. The study population having 59\% of low education status and $30 \%$ (31) are unaware to stick to the treatment and its complications and course and its complications.

The most common reasons of non-compliance is the lack of sufficient motivation for the treatment adherence as many mentioned is $61.4 \%$ in diabetics.

The most common cause of non-compliance is the lack of faith in the medication 12 (11\%), forgetfulness of daily medication 61 (58\%) and financial constraints for the drug treatment 32 (31\%).

In the studies in South India showed that major factors associated with non-compliance in chronic disease were found to be the asymptomatic course of Disease and nonavailability of free cost drugs from the local health centre pharmacy. The relatively asymptomatic course of the disease and lack of adequate knowledge about Disease in predispose patients may lead to non-adherence of the drug regimen. ${ }^{7}$

The systematic reviews confirm many patients with Diabetes took less than the prescribed amount of medication including both Oral Hypoglycaemic Agents and Insulin. ${ }^{9}$ Retrospective studies documented adherence to OHA therapy ranged from $36 \%-93 \%$ in patients on treatment for 6 - 24 months. Prospective studies documented that $67 \%$ $85 \%$ of OHA and Insulin adherence was $62 \%-64 \%$.

Guidelines from the ADA and the European Association for the Study of Diabetes (EASD) stress the importance of diet and exercise in the treatment of all stages of type 2 diabetes. 
In this study, 58\% (62) are non-adherent to the diet. With regard to diet, patients expressed a dislike for foods included in meal plans $47 \%$, whereas the educators considered social influences equally important barriers $47 \%$ and $6 \%$ are not able to follow the meal plan due to financial constraints.

30/45 minutes a day, at least 5 times a week/all 7 days exercise is needed for Indians. Insufficient physical activity kills 3.2 million people globally and around $23 \%$ of adults aged > 18 yrs. are insufficiently active. In view of the prevalence, global reach and health effect of physical inactivity the issue should be appropriately described as Pandemic with far-reaching health, economic, environmental and social consequences - Lancet July 2012.

However, despite strong clinical recommendations for individuals with a history of diabetes to adopt a healthier lifestyle, adherence to improved diet and exercise is poor. ${ }^{10}$ Although type 2 diabetes usually occurs in people over the age of 40 years, it is becoming increasingly common in children, adolescents and young adults due to reduced physical activity and unhealthy eating patterns leading to obesity. 10

\section{CONCLUSION}

Type 2 diabetes is a progressive disease and pharmacological treatment, diet, exercise, lifestyle changes are essential to maintain glycaemic control and reduce progress of complications. Even though adherence to medications leads to beneficial outcomes, but it is often poor. ${ }^{2}$ There are numerous reasons for poor adherence including age, social, education, cost of the treatment and lack of understanding of long-term benefits of treatment. Defective communication between Doctor and the patient often leads to noncompliance. ${ }^{2}$ Patients' understanding, recall and satisfaction have linked with compliance. We need to have a competent public health system along with innovative strategies, technology-based initiatives and an efficient use of existing resources. A multi-pronged approach is needed. It is important to develop prevention and control programs involving multiple agencies and innovative approaches to minimise the compliance in Diabetes management regime.

\section{REFERENCES}

[1] Rampal L, Rampal S, Azhar MZ, et al. Prevalence, awareness, treatment and control of hypertension in Malyasia: a national study of 16,440 subjects. J Public Health 2008;122(1):11-8.

[2] King DE, Mainous AG, Carnemolla M, et al. Adherence to healthy lifestyle habits in US adults, 1988-2006. Am J Med 2009;122(6):528-34.

[3] Janz NK, Becker MH. The health belief model: a decade later. Health Educ Q 1984;11(1):1-47.

[4] World Health Organization. Adherence to long-term therapies. Evidence for action. World Health Organization, Geneva, 2003.

[5] World Health Organigation: report on medication Adherence. Geneva, 2003.

[6] Guillausseau PJ. Impact of compliance with oral antihypergly cemicagents on health outcomes in type 2 diabetes mellitus: a focus on frequency of administration. Treat Endocrinol 2005;4(3):167-75.

[7] International Diabetes Federation. Diabetes and impaired glucose tolerance. IDF Diabetes Atlas, $5^{\text {th }}$ edn. Brussels, Belgium: International Diabetes Federation, 2012.

[8] Donnan PT, MacDonald TM, Morris AD. Adherence to prescribed oral hypoglycaemic medication in a population of patients with type 2 diabetes: a retrospective cohort study. Diabet Med 2002;19(4):279-84.

[9] Inzucchi SE, Bergenstal RM, Buse JB, et al. Management of hyper glycaemia in type 2 diabetes: a patient-centered approach. Position statement of the American Diabetes Association (ADA) and the European Association for the Study of Diabetes (EASD) Diabetologia 2012;55(6):1577-96.

[10] Praet SF, van Rooij ESJ, Wijtvliet A, et al. Brisk walking compared with an individualized medical fitness programme for patients with type 2 diabetes: a randomized controlled trial. Diabetologia 2008;51(5):736-46. 